\title{
Ortaokul Öğrencilerinin Bilim ve Fen Bilimleri Dersine Yönelik Tutumları
}

\author{
${ }^{*}$ Aslı Bahar ÇELIK ve ${ }^{2}$ Aslı GÖRGÜLÜ ARI \\ ${ }^{1}$ Fen Bilimleri Enstitüsü, Yıldız Teknik Üniversitesi, Türkiye \\ *2Eğitim Fakültesi, Matematik ve Fen Bilimleri Eğitimi Bölümü, Yıldız Teknik Üniversitesi, Türkiye
}

\begin{abstract}
Özet
$\mathrm{Bu}$ çalışmanın amacı ortaokul öğrencilerinin fen bilimleri dersine ve bilime yönelik tutumunu incelemektir. Katılımcıların görüşlerinin, ilgi, beceri, yetenek ve tutum gibi özelliklerinin belirlenebildiği betimsel tarama modeli öğrencilerin Bilime ve Fen bilimlerine karşı tutumlarını belirleyebilmek adına genel tarama modelleri içinden seçilerek kullanılmıştır. Araştırma İstanbul ili Sarıyer ilçesinde bulunan devlet okulunda öğrenim gören 46 beşinci, 36 altıncı, 60 yedinci ve 55 sekizinci sınıf öğrencilerinden olmak üzere toplam 197 ortaokul öğrencisi ile gerçekleştirilmiştir. Veri toplama aracı olarak Fen Bilimleri Dersi Tutum Ölçeği uygulanmıştır. Elde edilen verilerin, frekans ve yüzde oranları hesaplanmıştır. Araştırma sonuçlarına göre öğrencilerin fen bilimleri dersine karşı var olan tutumlarının olumlu yönde olduğu, ancak bilime karşı tutumlarının pozitif yönde olmadığı, bu konuda önyargılara sahip oldukları görülmüştür.
\end{abstract}

Anahtar Kelimeler: Bilim, Fen Bilimleri, Tutum

\begin{abstract}
The aim of this study is to examine the attitude of secondary school students towards science and science course. The descriptive survey model, in which participants' views, interests, skills, abilities and attitudes can be determined, was chosen from the general screening models in order to determine the attitudes of the students towards the Science and Science course. The research was carried out with 197 secondary school students (46 fifth, 36 sixth, 60 seventh , 55 eighth grade students) at the public school in Sarıyer, İstanbul. The Attitude Scale of Science Lesson was applied as a data collection tool. Frequency ratios of the data obtained were calculated. According to the results of the research, it was observed that the attitudes of the students towards the science course were positive, but their attitudes towards science were not positive and they had prejudices about this subject.
\end{abstract}

KeyWords: Historyof Science, ScientificAttitude, Secondary School

\section{Giriş}

Bilgiye hızla ulaştı̆̆ımız bu yüzyılda özellikle bilim ve teknolojideki her geçen gün meydana gelen değişimlere uyum sağlayabilen birey ve toplum yetiştirmek eğitimin ve ülkelerin görevleri arasında yer almaktadır.Sanayi, sağlık, endüstri gibi birçok alandaki ilerlemelerin temelinde aslında güçlü bir fen bilimleri eğitimi yer alır.Ülkelerin dünyadaki stratejik konumunu belirleyen etkenler, bu dallardaki buluşlar ve ileri teknoloji ile gerçekleşir.Bu konumun önemi sağlam temellere verilmiş fen bilimleri eğitimi başlar.Ayrıca bugüne damgasını vuran bilimsel ve teknolojik ilerlemelerin, gelecek yüzyılları da etkilemesi kaçınılmaz bir sonuçtur.Bu önemli parametreler açısından değerlendirildiğinde, güçlü bir gelecek ve güvenilir bir bilimsel altyapı hedefleyen ülkeler vatandaşlarının iyi birer fen bilimleri okuryazarı olması gerektiğinin bilincindedir.Bu bilinç gelişmiş ülkeler önde olmak üzere tüm ülkelerde fen eğitimini en iyi şekilde ilerletebilme çabası oluşturmaktadır.Fen bilimleri dersinde üst düzey zihinsel becerilerin gelişimi, kavrayarak öğrenme, karşılaşılan yeni sorunlara çözüm üretebilmek, kişisellikten uzak düşünme becerisini

*Aslı Bahar ÇELIKK: Adres: Fen Bilimleri Enstitüsü, Yıldız Teknik Üniversitesi, İstanbul Türkiye. E-mail adresi: aslicelikb@gmail.com DOI: 10.33793/acperpro.02.01.17 
geliştirmek gibi özelliklerin kazandırılabilmektedir.Fen, hayatın birçok alanında önemli bir yere sahiptir.Hayatın sürdürülmesi sağlığın korunması, en verimli ve sorunsuz üretimin sağlanması ve zihinsel, ahlaksal konuların amaçlarının karşılanması için en değerli bilgi fenin doğası içindedir [1].Bu amaçla ülkemizde de eğitim programlarında geniş kapsamlı değişikliklere yönelmiş ve yeni bakış açıları ortaya konarak köklü düzenlemeler yapılmıştır. 2013 yılından itibaren Fen Bilimleri Dersi Öğretim Programının temel amaçları arasında "Bilim insanlarının bilimsel bilgiyi nasıl oluşturduğunu, oluşturulan bu bilginin geçtiğisüreçleri ve yeni araşstırmalarda nasıl kullanıldığını anlamaya yardımcı olmak" ve "Bilimin,tüm kültürlerden bilim insanlarının ortak çabası sonucu üretildiğini anlamaya katkı sağlamak ve bilimsel çalışmaları takdir etme duygusunu gelişstirmek" ifadesi yer almaktadır [2].

Hodson'a (1992) göre fen eğitiminin üç temel amacı bulunmaktadır.Bunlar; 1.Bilimi öğrenmek (fen bilimi tarafından üretilen kanun, teori, kavram vb.), 2.Bilim hakkındakileri öğrenmek (bilim insanı, felsefe, tarih, toplumsal ve teknolojik bağlam, bilimsel yöntemler vb.) ve 3.Bilimin uygulamasını öğrenmektir (bilimsel çalışmalar içinde yer alabilmek) [3]. Öğrencilere bilimsel bilgileri direkt olarak aktarmayı tercih etmek yerine, öğrencilerin bilimsel düşünme becerilerine sahip, bilim ve fen okuryazarı olarak yetişmelerini sağlayacak olanakları sunmak gerekmektedir. Bilimsel bilgiyi anlayıp yorumlayabilen, bilimsel düşünme, akıl yürütme yeteneğine sahip olan ve bu özelliklerini günlük hayatında kullanabilen öğrenciler, yaşadığı çevreyi ve ülkesini daha ileriye taşıyabilecek bireyler olacaktır. Bilimin doğasını algılayabilen öğrenciler bilimsel bilginin hangi süreçlerden geçtiğini anlar ve günümüze gelene kadar uğradığı değiş̧iklikleri kavrarlar. Bu nedenle ögrencilerin fenle tanısmaları ve feni sevmeleri, fene yönelik olumlu tutumlar gelistirebilmeleri önem kazanmaktadır [4].

Gardner (1975) fene yönelik tutumu, "fen öğrenmeyi nesneleri, insanları ve hareketleri, durumları belli yöntemlerle değerlendirmeyi öğrenmek" olarak tanımlamıştır. Fene yönelik tutum fen, fen dersleri, laboratuar çalışması gibi nesnelere yönelik tutumu içermektedir. [5]. Son yıllarda ise duyuşsal hedefler, programlarda yer almaya başlamış ve duyusal davranışlar ölçülmeye çalışılmıştır. Öğrencilere belli duygu ve değerlerin kazandırılması amacı ile, eğitim programlarında duyuşsal hedeflere gün geçtikçe daha çok yer verilmesi, şüphesiz öğrencinin bilişsel hedeflerdeki başarısında, duyusal özelliklerin etkisinin saptanmış olmasının da bir sonucudur. Öğrencinin duyuşsal bazı özelliklerinin onun bilişsel hedeflerde ulaştığı basarı düzeyini etkilediği, yapılan araştırmalarda tespit edilmiştir[6].

Bu noktadan hareketle bu çalışmanın amacı ortaokul öğrencilerinin fen bilimleri dersine ve bilime yönelik tutumunu incelemektir.

\section{Yöntem}

\subsection{Araştırma Modeli}

$\mathrm{Bu}$ çalışmanın amacı ortaokul öğrencilerinin fen bilimleri dersine ve bilime yönelik tutumunu incelemektir.Bu doğrultuda araştırma betimsel bir çalışmadır.Betimsel çalışmalar aracılığıyla çalışılmakta olan olguya dair fertlerin tutum, görüş veya davranışlarının ortaya çıkarılması amaçlanmaktadır [7].

\section{2. Çalışma Grubu}

Araştırma İstanbul ili Sarıyer ilçesinde bulunan bir devlet okulunda öğrenim gören 46 beşinci, 36 altıncı, 60 yedinci ve 55 sekizinci sınıf öğrencilerinden olmak üzere toplam 197 ortaokul öğrencisi ile gerçekleştirilmiştir. Örneklemin belirlenmesinde kolay ulaşılabilir durum örneklemesine başvurulmuştur. Kolay ulaşılabilir durum örneklenmesinde, örneklem araştırmacının çalışmasını yürütmesi için uygun özelliktedir ve bu örnekleme ulaşmak kolaydır. Örneklem rastgele ya da sistematik olarak seçilemediği durumlarda tercih edilebilir [8]. 


\begin{tabular}{|c|c|c|c|c|c|c|c|c|}
\hline \multirow[b]{2}{*}{ SINIF } & \multicolumn{3}{|c|}{ DENEY } & \multicolumn{3}{|c|}{ KONTROL } & \multicolumn{2}{|c|}{ TOPLAM } \\
\hline & $\mathbf{N}$ & $\underset{\text { İçi }}{\text { \% Grup }}$ & \% Toplam & $\mathbf{N}$ & $\underset{\text { İçi }}{\text { \% Grup }}$ & \% Toplam & $\mathbf{n}$ & $\%$ \\
\hline 5. SINIF & 26 & 24,8 & 13,2 & 20 & 21,7 & 10,2 & 46 & 23,4 \\
\hline 6. SINIF & 20 & 19,0 & 10,2 & 16 & 17,4 & 8,1 & 36 & 18,3 \\
\hline 7. SINIF & 30 & 28,6 & 15,2 & 30 & 32,6 & 15,2 & 60 & 30,5 \\
\hline 8. SINIF & 29 & 27,6 & 14,7 & 26 & 28,3 & 13,2 & 55 & 27,9 \\
\hline TOPLAM & 105 & 100,0 & 53,3 & 92 & 100,0 & 46,7 & 197 & 100,0 \\
\hline CINSIYYT & $\mathbf{N}$ & $\begin{array}{c}\text { \% Grup } \\
\text { İçi }\end{array}$ & \% Toplam & $\mathbf{N}$ & $\begin{array}{c}\text { \%Grup } \\
\text { İçi }\end{array}$ & \% Toplam & $\mathbf{n}$ & $\%$ \\
\hline KIZ & 56 & 53,3 & 28,4 & 50 & 54,3 & 25,4 & 106 & 53,8 \\
\hline ERKEK & 49 & 46,7 & 24,9 & 42 & 45,7 & 21,3 & 91 & 46,2 \\
\hline TOPLAM & 105 & 100,0 & 53,3 & 92 & 100,0 & 46,7 & 197 & 100,0 \\
\hline
\end{tabular}

\subsection{Veri Toplama Araçlart}

Veri toplama aracı Kapıcı ve Akçay tarafından geliştirilen 5'li likert tipi bir ankettir. Geliştirilen ölçme aracının verileri ile cronbach alfa güvenirliği hesaplanmış ve 0,89 bulunmuştur. Elde edilen güvenirlik katsayısı bir ölçme aracı için yeterlidir.Öğrencilerden "Her zaman, Çoğu zaman, Ara Sıra, Nadiren, Hiçbir Zaman" şeklinde likert tipi olan ankete yanıt vermeleri istenmiştir [9].

\subsection{Verilerin Çözümlenmesi}

Elde edilen nicel veriler analiz edilmiş ve frekans ve yüzde oranları bulunmuştur.

\section{Bulgular}

Çalışmada fen bilimleri dersi tutum ölçeğinden elde dilen bulgular tablo halinde verilmiştir.

Tablo1. "Bilim adamları anlaşılması zor buluşlar yaparlar" Maddesine verilen cevapların frekansı

\begin{tabular}{cc|c|c|c|c|c|c|c} 
& $5 \mathrm{c}$ & $5 \mathrm{~d}$ & $6 \mathrm{c}$ & $6 \mathrm{~d}$ & $7 \mathrm{c}$ & $7 \mathrm{~d}$ & $8 \mathrm{c}$ & $8 \mathrm{~d}$ \\
\hline hiçbir zaman & 1 & - & - & 1 & - & 1 & 2 & - \\
\hline nadiren & 2 & - & 3 & 3 & 4 & 2 & 2 & - \\
\hline Ara sira & 4 & 3 & 7 & 2 & 5 & 6 & 7 & 4 \\
\hline çoğu zaman & 11 & 7 & 3 & 5 & 12 & 12 & 11 & 14 \\
\hline her zaman & 8 & 10 & 7 & 5 & 9 & 9 & 7 & 8 \\
\hline Toplam & 26 & 20 & 20 & 16 & 30 & 30 & 29 & 26 \\
\hline
\end{tabular}

"Bilim adamları anlaşılması zor buluşlar yaparlar." maddesine 5.Sınıfların \%39 her zaman, \%39 ise çoğu zaman, $\% 15$ ara sıra; 6. Sınıfların \%33 her zaman, \%22 çoğu zaman,\%25 ara sıra; 7. Sınıfların \%30 her zaman, \%40 çoğu zaman, $\% 25$ ara sıra, 8. Sınıfların \%20si her zaman, \%45 çoğu zaman \%18 ara sıra olarak cevap vermiştir. 
Tablo 2 "Fen bilimleri dersinde öğrendiğim şeyler günlük yaşamım için faydalıdır." maddesine verilen cevapların frekans1

\begin{tabular}{cc|c|c|c|c|c|c|c} 
& & & & & & & \\
& $5 \mathrm{c}$ & $5 \mathrm{~d}$ & $6 \mathrm{c}$ & $6 \mathrm{~d}$ & $7 \mathrm{c}$ & $7 \mathrm{~d}$ & $8 \mathrm{c}$ & $8 \mathrm{~d}$ \\
\hline hiçbir zaman & - & - & - & - & - & - & - & - \\
\hline nadiren & 2 & 1 & 2 & - & 1 & 1 & 5 & 4 \\
\hline Ara sıra & 5 & 3 & 4 & 2 & 9 & 7 & 3 & 3 \\
\hline çoğu zaman & 6 & 8 & 9 & 6 & 10 & 8 & 12 & 11 \\
\hline her zaman & 13 & 8 & 5 & 8 & 10 & 14 & 9 & 8 \\
\hline Toplam & 26 & 20 & 20 & 16 & 30 & 30 & 29 & 26 \\
\hline
\end{tabular}

"Fen bilimleri dersinde öğrendiğim şeyler günlük yaşamım için faydalıdır." maddesine 5.Sınıfların \%46 her zaman, \%30 çoğu zaman,\%17 ara sıra; 6. Sınıfların \%36 her zaman,\%42 çoğu zaman,\%17 ara sıra; 7. Sınıfların \%40 her zaman, \%30 çoğu zaman, $\% 27$ ara sıra; 8 . Sınıfların \%31 her zaman, $\% 42$ çoğu zaman, $\% 11$ ara sıra, $\% 16$ nadir olarak cevap vermiştir.

Tablo 3. "Fen Bilimleri dersi eğlencelidir." maddesine verilen cevapların Frekansı

\begin{tabular}{cc|c|c|c|c|c|c|c} 
& $5 \mathrm{c}$ & $5 \mathrm{~d}$ & $6 \mathrm{c}$ & $6 \mathrm{~d}$ & $7 \mathrm{c}$ & $7 \mathrm{~d}$ & $8 \mathrm{c}$ & $8 \mathrm{~d}$ \\
\hline hiçbir zaman & - & - & 2 & - & & - & - & 3 \\
\hline nadiren & - & - & 2 & 1 & 1 & - & - & 1 \\
\hline Ara sıra & 1 & 3 & 1 & - & 6 & 3 & 9 & 6 \\
\hline çoğu zaman & 6 & 7 & 4 & - & 12 & 10 & 16 & 10 \\
\hline her zaman & 19 & 10 & 11 & 15 & 11 & 17 & 4 & 6 \\
\hline Total & 26 & 20 & 20 & 16 & 30 & 30 & 29 & 26 \\
\hline
\end{tabular}

"Fen Bilimleri dersi eğlencelidir." maddesine 5.Sınıfların \%63 her zaman, \%8 ara sıra; 6.Sınıfların \%72 her zaman, \%8 Nadiren; 7. Sınıfların \%46 her zaman,\% 15 ara sıra; 8.Sınıfların \%18 her zaman, $\% 47$ çoğu zaman, \%27 ara sıra olarak cevap vermiştir.

Tablo 4."Fen Bilimlerini herkes anlayabilir ve yapabilir." maddesine verilen cevapların frekansı

\begin{tabular}{cc|c|c|c|c|c|c|c} 
& & & & & & & & \\
\hline hiçbir zaman & & 1 & & 1 & 1 & 1 & 2 & 2 \\
\hline nadiren & 4 & 5 & 1 & 1 & 5 & 3 & 8 & 5 \\
\hline Ara sıra & 8 & 3 & 7 & & 8 & 4 & 8 & 5 \\
\hline çoğu zaman & 6 & 5 & 3 & 7 & 7 & 8 & 8 & 5 \\
\hline her zaman & 8 & 6 & 9 & 7 & 9 & 14 & 3 & 9 \\
\hline Total & 26 & 20 & 20 & 16 & 30 & 30 & 29 & 26 \\
\hline
\end{tabular}


"Fen Bilimlerini herkes anlayabilir ve yapabilir." maddesine 5.Sınıfların \%30 her zaman,\%24 çoğu zaman \%25 nadiren; 6. Sınıfların \%44 her zaman, \%28 çoğu zaman \%19 ara sıra; 7. Sınıfların \%38 her zaman,\%25 çoğu zaman, \%20 ara sıra, $\% 13$ nadiren ; 8. Sınıfların \%22 her zaman, \%24 çoğu zaman,\%24 ara sıra,\%24 nadiren olarak cevap vermiştir.

Tablo5."Bilim adamı olmak eğlenceli olabilir." Maddesine verilen cevapların frekansı

\begin{tabular}{c|c|c|c|c|c|c|c|c} 
& $5 \mathrm{c}$ & $5 \mathrm{~d}$ & $6 \mathrm{c}$ & $6 \mathrm{~d}$ & $7 \mathrm{c}$ & $7 \mathrm{~d}$ & $8 \mathrm{c}$ & $8 \mathrm{~d}$ \\
\hline hiçbir zaman & 3 & 2 & 3 & 1 & 5 & 3 & 1 & 1 \\
\hline nadiren & 3 & 2 & 1 & 3 & 4 & 3 & 7 & 3 \\
\hline Ara sıra & 6 & 8 & 2 & 3 & 7 & 6 & 7 & 5 \\
\hline çoğu zaman & 4 & 4 & 7 & 9 & 3 & 5 & 7 & 7 \\
\hline her zaman & 10 & 4 & 7 & 16 & 11 & 13 & 7 & 10 \\
\hline Total & 26 & 20 & 20 & 16 & 30 & 30 & 29 & 26 \\
\hline
\end{tabular}

"Bilim adamı olmak eğlenceli olabilir" maddesine 5.Sınıfların \%30 her zaman, \%30 ara sıra,\%10u nadiren 6.Sinıfların $\% 64$ her zaman, $\% 14$ ara sira, $\% 11$ nadiren 7. Sinıfların $\% 40$ her zaman, \%22 ara sira, \%12 nadiren 8. Sınıfların \%31 her zaman, \%22 ara sıra, \%18 nadiren olarak cevap vermiştir.

Tablo 6. "Fen bilimleri dersi merakımı artırır." maddesine verilen cevapların frekansı

\begin{tabular}{cc|c|c|c|c|c|c|c} 
& $5 \mathrm{c}$ & $5 \mathrm{~d}$ & $6 \mathrm{c}$ & $6 \mathrm{~d}$ & $7 \mathrm{c}$ & $7 \mathrm{~d}$ & $8 \mathrm{c}$ & $8 \mathrm{~d}$ \\
\hline hiçbir zaman & - & - & 3 & - & 1 & 1 & - & 2 \\
\hline nadiren & 1 & 2 & 2 & - & 2 & - & 3 & 1 \\
\hline Ara sıra & 5 & 4 & 4 & - & 10 & 3 & 7 & 8 \\
\hline çoğu zaman & 8 & 7 & 6 & 7 & 7 & 13 & 12 & 6 \\
\hline her zaman & 12 & 7 & 8 & 9 & 10 & 13 & 7 & 9 \\
\hline Total & 26 & 20 & 20 & 16 & 30 & 30 & 29 & 26 \\
\hline
\end{tabular}

"Fen bilimleri dersi merakımı artıır." maddesine 5.Sınıfların \%41 her zaman, \%33 çoğu zaman,\%20 ara sıra ; 6. Sınıfların \%47 her zaman,\%36 çoğu zaman,\%11 ara sıra ; 7. Sınıfların \%38 her zaman,\%33 çoğu zaman,\%22 ara sıra; 8. Sınıfların $\% 29$ her zaman, \%33 çoğu zaman, $\% 27$ ara sıra olarak cevap vermiştir. 


\section{Tartışma ve Sonuc}

$\mathrm{Bu}$ çalışmanın amacı ortaokul fen bilimleri dersine ve bilime yönelik tutumunu incelemektir. $\mathrm{Bu}$ amaç doğrultusunda gerçekleştirilen çalışma betimsel bir araştırma olup veri toplama aracı olarak Fen Bilimleri dersi tutum ölçeği, 46 beşinci, 36 altıncı, 60 yedinci ve 55 sekizinci sınıf öğrencilerinden olmak üzere toplam 197 ortaokul öğrencisine uygulanmıştır.

Fen Bilimleri dersi tutum ölçeği verilerine dayanarak elde edilen sonuçlarına göre, tüm sınıflarda Fen Bilimleri dersine karşı olumlu bir tutum olduğu görülmüştür. "Fen Bilimleri dersi eğlencelidir." maddesine 5.Sınıfların \%63 her zaman, $\% 8$ ara sıra; 6.Sinıfların $\% 72$ her zaman, \%8 Nadiren; 7. Sinıfların $\% 46$ her zaman,\% 15 ara sira; 8.Sınıfların $\% 18$ her zaman, $\% 47$ çoğu zaman, $\% 27$ ara sıra olarak cevap verdiği görülmektedir. Öğrenciler fen dersini eğlenceli bulmakta ancak bu oran 8. Sınıflarda düşmektedir. "Fen bilimleri dersi merakımı artırır." maddesine 5.Sınıfların \%41 her zaman, \%33 çoğu zaman,\%20 ara sıra ; 6. Sinıfların \%47 her zaman,\%36 çoğu zaman,\%11 ara sıra ; 7. Sınıfların \%38 her zaman,\%33 çoğu zaman,\%22 ara sıra; 8. Sınıfların \%29 her zaman, \%33 çoğu zaman, $\% 27$ ara sıra olarak cevap vermiştir.

Çalışma sonuçlarına göre öğrencilerin Fen Bilimleri dersine yönelik tutumları sınıf seviyelerine göre değişkenlik göstermektedir. Fen Bilimleri dersine yönelik olumlu tutum 5. sınıftan 8. sınıfa doğru gidildikçe azalmaktadır. Bunun sebebi, 5. Sınıf kazanımlarının 7. ve 8. sınıflara göre daha basite indirgenmiş ve sözel ifadelerin yer aldığ görsellerle anlatımın yoğunlaştığı, 8. sınıfa doğru gidildikçe kazanımların fizik, kimya konuları içermesi ve matematik işlemlerini içeren konular olması olabilir. Bir başka açıyla 8. sınıfların uzun yıllardır Fen Bilimleri eğitimi alması ögrencide ilgiyi azaltmış olabilir. Stark ve Gray (1999) ortaokullarda fen ve bilime yönelik tutumun, ilk okula göre düşük olduğunu belirtmiş, fen bilimlerine yönelik tutumun ergenliğe doğru düştüğünü söylemiştir [10] Tal ve diğerleri (2000) 10 yaşından 14 yaşına doğru gidildikçe fen dersine yönelik ilgi ve motivasyonda düşüş olduğunu vurgulamışlardır [11]. Pell ve Jarvis (2001), [12] Jarvis ve Pell (2002) çalışmaları yaş arttıkça fene olan motivasyonun düştüğünü [13], George (2000) sınıf seviyesi ilerledikçe öğrencilerin fen bilimleri dersine e yönelik tutum puanlarının düşme eğilimi gösterdiğini çalışmasında göstermiştir [14].

"Fen bilimleri dersinde öğrendiğim şeyler günlük yaşamım için faydalıdır." maddesine 5.Sınıfların \%46 her zaman, \%30 çoğu zaman,\%17 ara sıra; 6 . Sınıfların \%36 her zaman,\%42 çoğu zaman,\%17 ara sıra; 7. Sınıfların \%40 her zaman, \%30 çoğu zaman,\%27 ara sıra; 8 . Sınıfların \%31 her zaman,\%42 çoğu zaman, \%11 ara sıra,\%16 nadir olarak cevap verdiği görülmektedir. Öğrencilerin uygulama öncesi Fen Bilimleri dersine karşı var olan tutumlarına bakıldığında, öğrendikleri bilgilerin günlük hayatta da kullanabileceklerini, kendileri için fayda sağlayacağını düşünmektedirler. "Bilim adamları anlaşılması zor buluşlar yaparlar." maddesine 5.Sınıfların \%39 her zaman, \%39 ise çoğu zaman, \%15 ara sıra; 6. Sınıfların \%33 her zaman, \%22 çoğu zaman,\%25 ara sıra; 7. Sınıfların \%30 her zaman, $\% 40$ çoğu zaman, $\% 25$ ara sıra, 8. Sınıfların \%20si her zaman, $\% 45$ çoğu zaman \%18 ara sıra diye cevap verdiği görülmektedir. Öğrencilerin Bilim adamlarının yaptıkları buluşları anlaşılması zor buldukları görülmektedir.

Fene ve bilime yönelik tutumların değiştirilmesi, elbette ki hızla ulaşılabilecek bir şey değildir. Bu yönde bilim ve Fen bilimleri dersine yönelik olulu tumtumların geliştirilmesi için çalışmalar yapılmalıdır. Bu amaçla; Öğrencilerin Fen bilimleri dersini sevdiği ölçüde olumlu tutum geliştireceğini göze alırsak, öğrencilere iyimser bir yaklaşımla bulunarak,, öğrencinin fen dersine olan ilgisini artırılmalıdır. Alternatif ve etkili yöntemlerle fen dersi ilgi çekici hale getirilmelidir.

Sınıf düzeyleri arasındaki fen bilimlerine yönelik tutum farklılığını gözetirsek bu durumu en aza indirgemek için, öğrencilerin 5.Sınıftan itibaren Fen Bilimleri dersine karşı geliştirdikleri olumlu tutumu sürdürmeleri sağlanmalıdır.Öğrencinin 8.Sınıfa geldiğinde neden olumlu tutumunda azalma olduğu araştırılmalıdır. 


\section{Kaynakça}

[1] Chapman, B., "The Overselling of Science Education in the 1980s", Teaching Science, Ed. by Ralph Levinson, London, Open Unv. Press, 1995

[2] MEB (Milli Ĕ̆itim Bakanlığı), (2013). Fen Bilimleri Dersi (3,4,5,6,7 Ve 8.Sinıflar) Öğretim Programı. Ankara: TalimTerbiyeKuruluBaşkanlığı. http://ttkb.meb.gov.tr/program2.aspx adresinden 22.02.2017 tarihinde erişilmiştir

[3] Henze, I., Driel, J. V. And Verloop, N. (2007).“The Change of Science Teachers' Personal Knowledge about TeachingModels and Modelling in the Context of Science Education Reform", International Journal of Science Education, 29-15, 1819-1846.

[4] Hamurcu, H., Fen Bilgisi Ögretiminde Etkili Tutumlar, Egitim Arastırmaları Dergisi Sayı.8, 144-152, 2002.

[5] Gardner, P. L. (1975). Attitudes to science: A review. Studies in Science Education, 2, 1-41

[6] Tepe, D., Ögrencilerin Fen Derslerine Karsı Tutumları ile Basarıları Arasındaki iliski, (Yayımlanmamıs Yüksek Lisans Tezi), Marmara Üniversitesi,_stanbul, 1999.

[7] Creswell, J. W. (2008). Educational Research: Planning, Conducting, And Evaluating

[8] Fraenkel, J. R., Wallen, N. E., \& Hyun, H. H. (2012).How To Desıgn And Evaluate Research In Education (8th Ed.). New York: Mc Graw Hill.

[9] Kapici H.Ö., Akçay H., "Middle School Students Attitudes toward Science Scientists Science Teachers and Classes", The Asia-Pasific Forum on Science Learning and Teaching, vol.17, pp.1-22, 2016

[10] Stark, R., and Gray, D., Gender Preferences in Learning Science, International Science Education, Vol. 21, 633 643, 1999.

[11] Tal, T., Geier, R. and Krajcik, J., Urban Students' Beliefs about Science in Inquiry-based Classrooms, Paper Presented at AERA Conference, New Orleans, 1-30, April 2000.

[ 12] Pell, T. and Jarvis, T., Developing Attitude to Science Scales for Use with Children of Ages from Five to Eleven Years, International Journal of Science Education, Vol. 23, 847-862, 2001.

[ 13] Jarvis, T. and Pell, A., Changes in Primary Boys' and Girls' Attitudes to School and Science During a Two Year Science In Service Programme, the Curriculum Journal, Vol.13, 43-69, 2002.

[14] George, R., Measuring Change In Students' Attitudes Toward Science Over Time: An Application Of Latent Variable Growth Modeling, Journal of Science Education and Technology, Vol. 9, 213-225, 2000. 